\title{
Gallus Sapiens: um PRojeto artístico, de Victor de la RocQue, SOb UM OLHAR ANTROPOLÓGICO
}

John Fletcher e Ernani Chaves ${ }^{1}$

UFPA, PA, Brasil

\begin{abstract}
O presente artigo visa a delinear um olhar interpretativo acerca do projeto artístico Gallus Sapiens, do artista plástico Victor De La Rocque. Este projeto, em cada uma de suas três distintas partes, gera significados politicos, criticos e poéticos, além de sinalizar culturalidades de países não hegemônicos; fatores estruturais e políticos sobre condições de percepção; pedagogias incidentes; e diálogos politizados e politizantes para os diversos grupos sociais. Com o uso metodológico do interpretativismo de Clifford Geertz, problematizado pelas perspectivas PósColonial e Decolonial de autores como Walter Mignolo, Homi Bhabha e Nestor Garcia Canclini, também utiliza intelectuais do universo da filosofia, caso de Michel Foucault, Ernani Chaves e Jacques Rancière; outros da antropologia, caso de Arnd Schneider Christopher Wright, George Marcus e Victor Turner; e das artes visuais, caso de Roselee Goldberg, Beatriz de Medeiros e Orlando Maneschy. O projeto Gallus Sapiens, permeado por significados caóticos e confituosos, é aqui, portanto, analisado sob a perspectiva do estar-junto em sua essência, atrelado aos caminhos e descaminhos de se viver em um mundo irregular, posto às margens dos centros geopolíticos, inclusive nacionais.
\end{abstract}

Palavras-Chave: Gallus Sapiens, Victor De La Rocque, arte contemporânea, interpretação

1 John Fletcher é aluno de doutorado no Programa de Pós-Graduação em Antropologia (PPGA/ UFPA), Belém, PA, Brasil. Contato: coustonjf@gmail.com. Ernani Chaves é Professor Associado III da Faculdade de Filosofia e Professor Permanente do Programa de Pós-Graduação em Antropologia, ambos da UFPA, Belém, PA, Brasil. Contato: erna.nic@hotmail.com. Os autores agradecem à CAPES pela concessão de bolsa de Doutorado, à pesquisadora Dra. Maria Beatriz de Medeiros (UnB), pelas preciosas considerações durante o 22० Encontro da Associação Nacional de Pesquisadores em Arte, e ao artista Victor De La Rocque (PPG-Arte/UnB) pela gentileza ao compartilhar suas experiências conosco. 


\section{CONSIDERAÇõEs INICIAIS}

O que convencionamos chamar de contemporâneo ${ }^{2}$, acreditamos, tem possibilitado frentes para se problematizar antigas fronteiras de entendimento. Para além de algumas dessas categorias em processos de luta e de desmantelamento - caso de muitas separações binaristas e reducionistas dentro de uma visão moderna para a lógica social dos estar-junto -, chama-nos a atenção como o universo das artes visuais, eixo cultural oscilante entre a objetividade e a subjetividade de sujeitos culturalmente diversos, desempenha um papel persistente para se compreender horizontes dinâmicos, talvez mais inclusivos e menos autoritários (Sarlo 2000).

Sob essa ótica, e seja por perceber, dentro de nosso mundo ocidental e urbano, o crescente valor midiático e econômico alcançado por inúmeras obras- mencionemos as quantias de dinheiro e a publicidade obtidas por conhecidos artistas como Damien Hirst, Jeff Koons, Andreas Gursky, por exemplo, além da ampliação da circulação global de brasileiros, como é o caso de Beatriz Milhazes, Vik Muniz e Adriana Varejão -, seja por pontuar o quanto artistas e produtores culturais têm se tornado parte necessária da produção de nossos dias (Mouffe 2007), este universo, produzido no domínio experimental criativo de sociedades integradas ao modelo capitalista de negociação, passou a deflagrar referências aos sucessos e aos fracassos da globalização (García Canclini 2012), bem como aos diferentes modos de se pensar e de se produzir esteticamente em um mundo alavancado por repertórios e produtos irregulares, mutantes, dinâmicos e pensativos (Plaza 1987; Sarlo 2000; Rancière 2012).

De acordo com o antropólogo Walter Mignolo (2010), desde o século XVIII, a esfera composta pelas artes foi apropriada pelo pensamento imperial e transformada em uma limitação conceitual e ocidental do que seria arte - e se antes fora sedimentada no sublime e no belo, hoje, parece se revelar vinculada, de acordo com muitos autores pós-modernos, a um vazio autorreferencial para sua autorrecreação (ver também Hall, 2009). Com o intuito de propor outro tipo de reflexão sobre experiências visuais feitas a partir de relações contextuais distintas e que não poderiam ser encerradas de acordo somente com protocolos do centro, este autor, ao lado de tantos outros dos debates Pós-Colonial ${ }^{3}$ e Decolonial $^{4}$, tem reafirmado uma nova agenda interpretativa e destituída dos processos de colonização do poder, do ser, do ouvir, do fazer e do ver, de maneira a tangenciar a premissa de Edward Said (1994) de pensamento em contraponto, ou seja, um pensamento o qual encara diferentes experiências como parte de um conjunto de histórias interligadas e sobrepostas, cada uma das quais com seu próprio programa e ritmo de desenvolvimento, com suas próprias formações internas e o seu sistema de relações externas, todos coexistindo e interagindo entre si.

2 Partimos da ideia de contemporâneo semelhante à proposta por Agamben (2009: 62), quando coloca que este se prediz ao sujeito manter fixo o olhar no seu tempo, "para nele perceber não as luzes, mas o escuro".

3 Os debates em torno do Pós-Colonial possuem algumas de suas primeiras considerações nos escritos do psicólogo martinicano Frantz Fanon, na década de 1950; nos do crítico literário Edward Said, na década de 1990; e no papel atuante de intelectuais das chamadas periferias globais em universidades europeias e americanas, na década de 1980 e 1990, com os nomes de Stuart Hall, Mary Louise Pratt, Homi Bhabha, Gayatri Spivak, dentre outros. 4 Não podemos deixar de destacar que algumas das insinuações para esta problemática da colonialidade do ver e do ser na América Latina já apareceram, mesmo sem uma organização ainda demarcada, por volta dos anos 1970, nos escritos do antropólogo Darcy Ribeiro; nos debates iniciados pela teoria da dependência, com Aníbal Quijano; na filosofia e na sociologia de Enrique Dussel e Orlando Fals Borda; através dos debates de Robert Ricard; e, alguns anos mais tarde, pela teoria da colonização do imaginário, de Serge Gruzinski (Mignolo 2010). 
Nesse sentido, e de maneira relacionada com o debate proposto por Walter Mignolo e também por outros autores não somente das mencionadas perspectivas Pós-Colonial e Decolonial, o presente artigo visa a traçar uma leitura interpretativa do projeto artístico Gallus Sapiens, de Victor De La Rocque, a fim de evidenciar um olhar sobre cada uma de suas três etapas e de como elas podem gerar significados políticos, críticos e poéticos não somente para a dimensão local de sua proposição - neste caso, a cidade de Belém, no Estado do Pará -, mas significados relevantes para nosso contemporâneo assimétrico e polifônico. Sob este horizonte, também pretendemos sinalizar culturalidades de países não hegemônicos, fatores estruturais e políticos sobre condições de percepção e pedagogias incidentes e diálogos politizados e politizantes para os diversos grupos sociais (Ramírez 2004; Geertz 2008; Lucero 2011).

O projeto Gallus Sapiens está amplamente, mas não somente, ancorado em operações ligadas à performance ${ }^{5}$. Como bem evidenciado por inúmeros dos olhares antropológicos para esta forma de expressão, muito em voga para as artes plásticas a partir da década de $1960^{6}$, a performance, espécie de prioridade antropológica sobre eventos rituais como suportes para a análise social (Turner 1987), é caracterizada por "uma noção interdisciplinar a qual busca evidenciar as coisas que escapam das classificações e dos paradigmas da ordem" (Silva 2005: 42). Com engrenagens múltiplas, as quais estabelecem universos muitas vezes distintos para o território do teatro em perspectiva com o território das artes visuais ${ }^{7}$ (ver Gómez-Peña 2005; Schechner 2006; Goldberg 2006; Auslander 2006), a performance, não obstante, traduz ações simbólicas, permeadas de significados localizados (Geertz 2008).

Em termos mais recentes para o entendimento deste fenômeno, distintas ideias podem considerá-lo por: operador analítico para certo tipo de comportamento que se coloca entre o performer e as audiências (Schechner 2006 ;Carlson 2010); uma provocação para se pensar e questionar a organização do pensamento social (Kirshenblatt-Gimblett 1998; Marcus 2004); prática associada ao espetáculo (Sibila 2010); existência presencial cuja ontologia não deveria ser traída pela economia da reprodução (Phelan 1993); espaço de experimentação fora dos campos monodisciplinários (Gómez-Peña 2005); ou mesmo aliança potencial para o campo da antropologia, uma vez que este diálogo não somente critica a antropologia por um suposto não-esteticismo interior ao seu campo, como a chama para um exceder antigas representações tradicionais e funções documentais, conforme já advogado, ainda que em termos, na prática, somente teoricamente, pelo ethnographic turn do Seminário de Santa Fé8 (Marcus 2004; Schneider 2008; Schneider \& Wright 2010). Ao implicar em uma dimensão interacional conectada por sua prá-

$5 \mathrm{O}$ campo da performance se conforma como um continuum de ações humanas as quais variam desde rituais, esportes, jogos, entretenimento popular, artes performativas (teatro, dança, música), até performances cotidianas sob os marcadores de raça, gênero, classe social, profissional, tratamentos de cura (do xamanismo às cirurgias), mídia e internet. Não existe limite fixável, culturalmente ou historicamente, para o que é performance. No decorrer deste continuum do fenômeno, novos gêneros são adicionados, enquanto outros podem ser questionados (Gómez-Peña 2005; Schechner 2006).

6 Carlson (2010) evidencia os questionamentos advindos, neste momento, quanto ao caráter institucional da arte, com aspectos de importância mais ligados ao processo que ao artista e obra. A performance neste contexto, para o autor, é herdeira do futurismo por meio do dadaísmo e dos happenings.

7 A performance para o território das artes visuais apresenta uma semântica, em vários aspectos, distinta da do teatro. Além de poder ter sua continuidade em outros suportes (vídeo, fotografia, instalação, pintura etc.) e em outros tempos, por exemplo, pode possuir uma relação de plateia, por vezes, mais elástica (pensamos nas performances cujo propósito é o de não haver testemunhas, mas de se comportar como resíduo) (Goldberg 2006).

8 O Seminário de Santa Fé ocorreu na Escola de Investigação Americana de Santa Fé, Nuevo México, em 1984, e teve seu tema central em torno da redação do texto antropológico, da autoridade etnográfica e da relação entre pesquisador e seus pesquisados (Rocha \& Eckert 1998). 
tica, os lócus da performance podem evidenciar, portanto, contornos linguísticos ao deslocar o olhar do enunciado e de seu conteúdo para os modos de enunciação em conexão com práticas sociais em contextos específicos (Schechner 2006; Carlson 2010; Lotufo 2013).

Como bem observou Bhabha (2012), as produções artísticas contemporâneas não devem ser compreendidas se abdicadas de seus tempos e lugares contextuais, mesmo sob a égide intercultural já tão referendada atualmente. Trata-se, para além de traçar interpretações visuais singulares de sociedades diferentes, de um entendimento o qual fornece dimensões autocríticas para as esferas ainda não experimentadas, as reprocessadas e as que se colocam em um lugar de compartilhamento constituinte com seu público fruidor (Bhabha 2003; Bhabha, 2012).

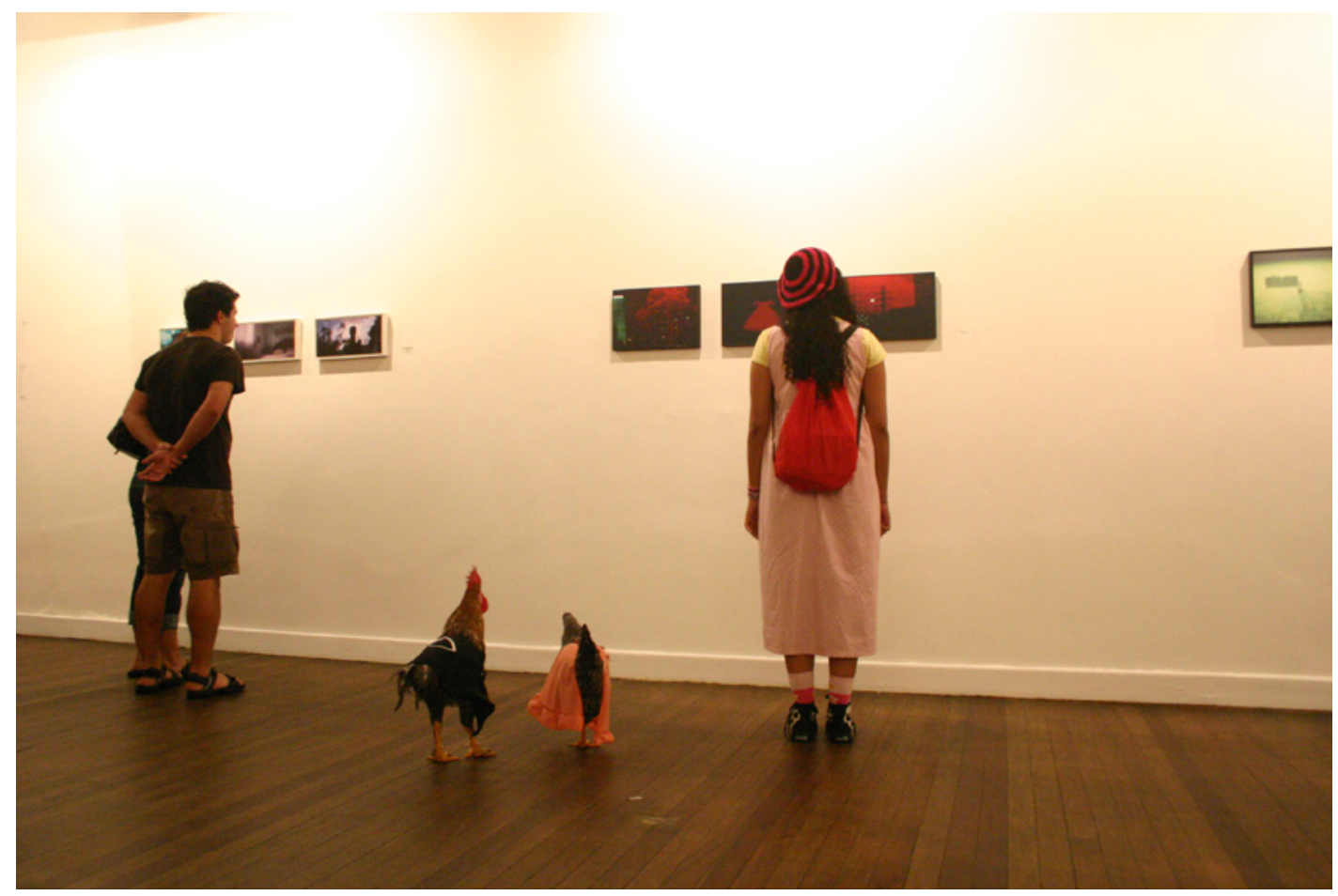

Figura 01 A. Gallus Sapiens Parte 01, de Victor De La Rocque, apresentado no XIII Salão Unama de Pequenos Formatos. Fotografia: Victor De La Rocque.

\section{Gallus Sapiens Parte 01: a Ave que Rı}

O início do projeto artístico de Victor De La Rocque, o qual pode ser arquitetado como uma trilogia, remonta ao ano de 2007, quando da participação da performance Gallus Sapiens Parte 01 no 13 Salão Unama de Pequenos Formatos, sob curadoria de Emanuel Franco (Figura 01).

Esta primeira apresentação contou, basicamente, com um galo e uma galinha ${ }^{9}$, vestidos em trajes "formais e distintos", soltos na área da exposição para se integrar ao burburinho do

9 Carlson (2010) evidencia como animais podem ser componentes discursivos para a performance quando colocados nestas situações discursivas frente a uma audiência, concepção convergente com a primeira etapa de Gallus Sapiens. 
vernissage e dos comes e bebes. Neste enredo, vale destacar, podemos conceber que o artista propôs uma narrativa explicitamente crítica e sardônica quanto ao papel de sujeitos no universo das artes visuais, sejam eles fruidores ou propositores/ fruidores, de maneira a nos questionar, a partir das duas aves, uma condição de fragilidade do ser para tentar conquistar o seu lugar ao sol, mesmo em meio ao terreno das precárias relações artísticas e sociais.

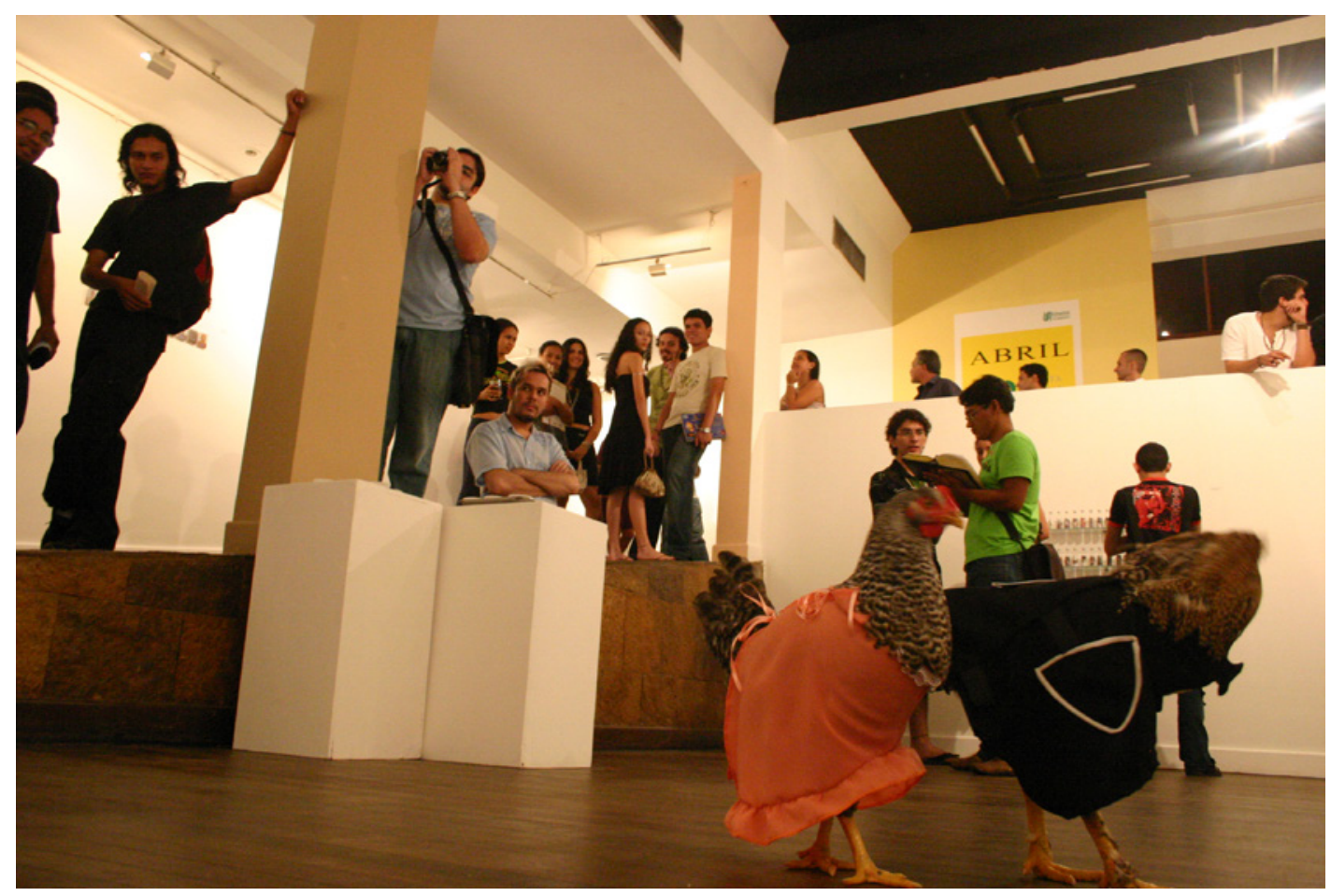

Figura 01 B. Gallus Sapiens Parte 01, de Victor De La Rocque, apresentado no XIII Salão Unama de Pequenos Formatos. Fotografia: Victor De La Rocque.

E como se não bastasse nos fazer problematizar os limites entre entendimento e desconexão (afinal, nós estamos abertos a perceber as artes contemporâneas, ou só fingimos melhor que as aves, no final das contas?), entre inserção artística e medo de exclusão (seremos em algum momento devorados?) e entre as artes em suas diversas facetas (e aqui podemos pensar nas artes plásticas como expressão, como impressão, como bens de consumo, como oportunismo, como hype, dentre tantas outras chaves de leitura), os animais puderam se mesclar aos demais visitantes tão naturalmente, conforme evidenciado principalmente pela Figura 01-A, que o papel dos pedigrees institucionais pôde, pelo menos para nós, igualmente ser colocado em xeque - a institucionalização da arte contemporânea não celebra, muitas vezes, conquistas artísticas e jogos de linguagens extremamente elitistas e herméticos para leitores mesmo habituais?

De uma forma relacional, estas aves, integradas formalmente a um santuário artístico de autoridades (ir)racionais, também nos evidenciaram outras ausências alocadas em nós mesmos. Neste caso, uma dessas ausências seria a da verdade do ser e a relação desta com os marcadores do poder e do saber, ambos territórios separados e não pertencentes aos domínios um do outro (Foucault 2013). Esta noção de verdade, termo equilibrista entre a falácia, os interesses e o esquecimento, reafirma-se, a partir de nossos olhares sobre a criação do artista, como entendimento utópico, instrumentalizado erroneamente por muitos para se cumprir uma tabela diária de ações vazias e como veículo de preceitos cínicos os quais, jocosamente, transvaloram todos os valores (Chaves 2013; Pelbart 2014). 
No que tange os preceitos filosóficos sobre o cinismo, Chaves (2013) pontuou que, desde a complexa filosofia de Diógenes, este foi apagado da história do pensamento e da vida cotidiana, de maneira que o cínico deixou de ser o enunciador da verdade (um cínico maior) para tornar-se aquele sujeito que sabe o preço de tudo, mas não sabe o valor de nada (um cínico menor), sorte de modelo de crítica e prática de vida caracterizada pela insolência e pelo escândalo (ver também Tiburi 2014). Muito aproximável das proposições estéticas de De La Rocque, este terreno de pensamento cínico reflete os auspícios do devir insolente, visto também encenar um discurso para a arte contemporânea que problematiza uma parcela do atual modelo social e econômico como estrutura de relações, se não falidas, no mínimo contraditórias, permeadas por bur(r)ocracias e por alianças particulares e simuladas para se obter interesses individuais.

Embora tais apontamentos cínicos dos discursos elaborados por Victor De La Rocque possam ganhar significação conosco, não deixa de ser pertinente colocar a própria posição do artista sobre seu projeto para corroborar com nossos argumentos:

Meu trabalho é me jogar nesses abismos e nesses riscos. Eu gosto de correr riscos. Tenho que parar novamente com a minha preguiça, pois é um torpor que veio com esse circuito vicioso. Entrei nele para correr riscos e fiquei viciado no seu conforto. Talvez esteja querendo levar um chute do circuito. Sou uma farsa declarada, só que acreditam em mim. Eu, às vezes, minto direito, e a galera realmente acredita, mas na verdade é tudo mentira, tudo cinismo. Preciso me colocar num envolvimento a ponto de arriscar minha existência, competência, credibilidade, ou o que quer que seja (Victor De La Rocque, Comunicação Pessoal).

A arte contemporânea, e a obra de Victor De La Rocque, por exemplificação, ajuda-nos “a esboçar possibilidades composicionais fugidias, pois, vivas" (Medeiros 2011:34), de teor crítico e também filosófico. E se, nas palavras do artista, encontramos uma deferência ao risco como parte integrante do projeto Gallus Sapiens, este recorte inicial desta trajetória artística pode acentuar, acreditamos, o retraçamento fronteiriço, subjetiva e empiricamente, de sujeitos quanto às suas maneiras de conceber o entorno e a si mesmos (García Canclini 2012), bem como proporciona uma sistemática inversão aos modelos de artes apresentados na Europa e nos Estados Unidos, visto dar continuidade a um debate (auto)crítico sobre questões sociais à frente de elementos de percepção (Lucero 2011).

\section{Gallus Sapiens Parte 02: Triunfo Galiforme (?)}

Na esteira das concepções iniciadas em 2007, a segunda parte ${ }^{10}$ do projeto Gallus Sapiens foi apresentada no 26 Salão Arte Pará, em 2008, sob curadoria de Alexandre Sequeira, Emanuel Franco e Orlando Maneschy. Neste evento, a mencionada proposição artística adquiriu o Grande Prêmio da mostra competitiva, juntamente com a pintura de Thiago Martins de Melo, intitulada Sad Goat Redux 3. Diferentemente da primeira parte de Gallus Sapiens, esta etapa em questão contou com a ação do próprio artista e se desenvolveu em outros três atos-aparições

10 Esta ação-performance também foi apresentada, com suas devidas adaptações, em Brasília, no ano de 2010, durante o evento Performance Corpo Política e Tecnologia, sob curadoria de Beatriz de Medeiros; em Bogotá, também no ano de 2010, durante o evento Trampolim Itinerante e Encuentro de Artes Relacionares de ASAB (Academia Superior de Artes de Bogotá); e no MAM, Rio de Janeiro, no ano de 2011, para o Festival Performance Arte Brasil, projeto curado por Daniela Labra e co-curado por Orlando Maneschy, com a apresentação de um panorama de artistas da performance do país - evento este o qual, além de Victor De La Rocque, trouxe Armando Queiroz e Orlando Maneschy para representar o Norte brasileiro. 
distintos pela cidade de Belém, unidos todos pelo mesmo eixo conceitual: Glória Aleluia e a Mão de Deus; Come, Ainda Tens Tempo; e Entre os Meus e os Seus (Figura 02 A, B e C) (Maiorana et al 2009).

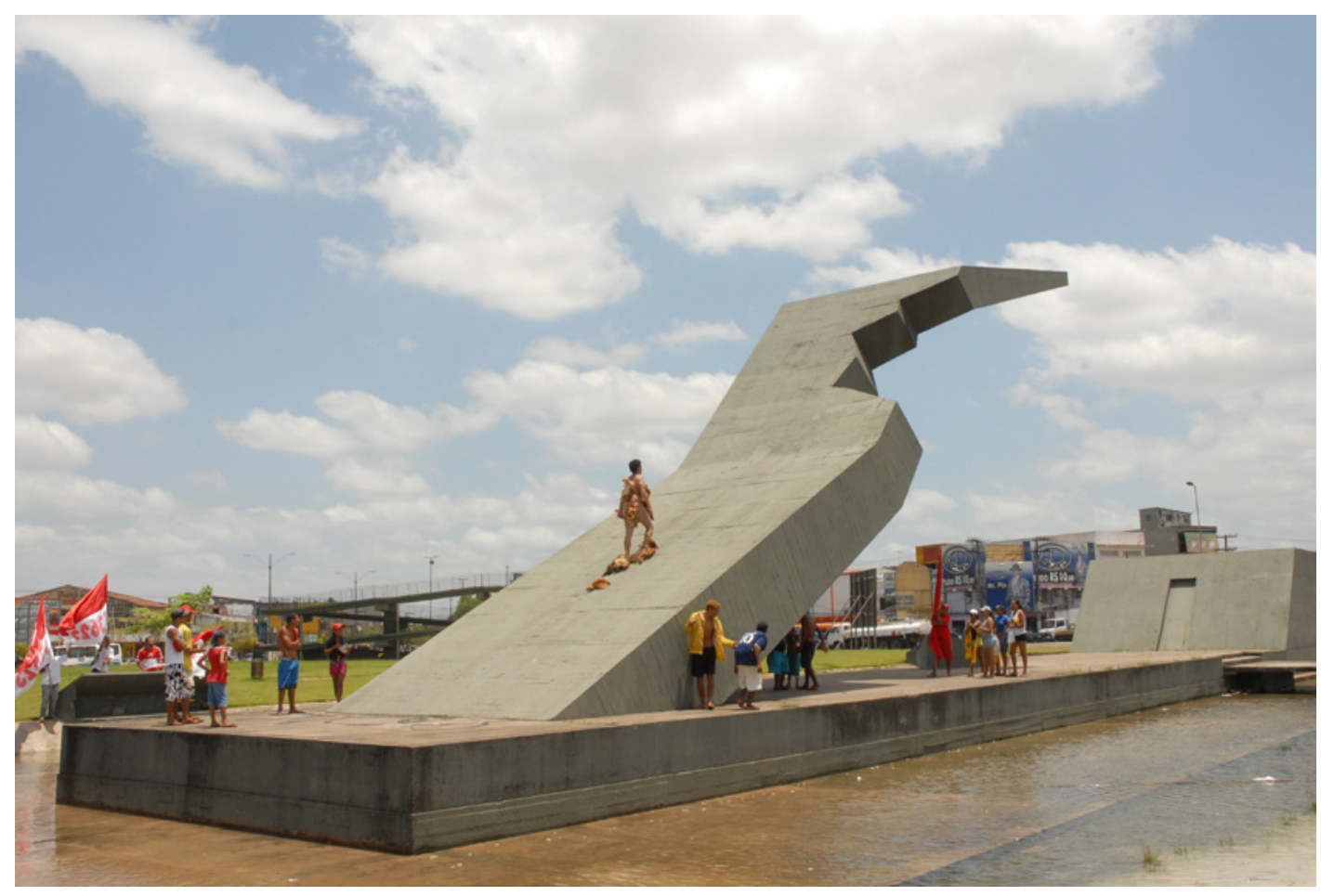

Figura 02 A. Gallus Sapiens Parte 02, de Victor De La Rocque, apresentado na 27º Edição do Salão Arte Pará. $1^{\circ}$ ato aparição, Glória Aleluia e a Mão de Deus. Fotografia: Victor De La Rocque.

Dando prosseguimento à ideia de "viver escandalosamente como os cínicos" (Chaves, 2014: 70), os três atos políticos e distintos de De La Rocque mantiveram referências à natureza humana e, conforme descrito por Maneschy (2009: 45), "ampliaram o corpo do artista, para além do simples ato de se vestir, procurando estabelecer um corpo comum, constituído pela soma (ou pelo embate) das duas espécimes". Tal qual uma entidade de algum culto afroindígena ${ }^{11}$, sua passagem por lugares-símbolos de poder belemenses (o Monumento à Cabanagem, projetado pelo arquiteto Oscar Niemeyer; a fachada do Museu Histórico do Pará, local de ocorrência do Salão Arte Pará; e a Avenida Presidente Vargas, situada na área comercial da cidade), vestida por vinte galinhas vivas compradas em feiras locais (algumas dessas galinhas morriam no processo da ação), fez-nos insinuar estados de consciência alienados e alienantes, visto este ser criado pelo artista perambular, estranhamente, entre o cansaço, a sofreguidão e o clamor silencioso por uma ajuda ausente. Conforme destacado pelo artista (Comunicação Pessoal), o primeiro ato-aparição, Glória Aleluia e a Mão de Deus, ocorrido no Monumento à Cabanagem, localizado em uma área que correspondia à antiga entrada, por vias terrestres, da cidade de Belém, representou o homem galiforme em sua busca pela salvação de sua vida-bandalha. No que para o mesmo se apresentava como uma espécie de corredor-escada rumo aos céus - corredor-escada este materializado pela mão projetada por Niemeyer, conforme observado na Figura 02-A -, seu primeiro chamado, estrategicamente, alocou-se em um portal de salvação e encontrou somente a indiferença de Deus.

11 Este termo, cunhado por Sarraf (2012), refere-se à presença de matrizes indígenas e africanas nos modos de vida praticados e compartilhados na Amazônia. 


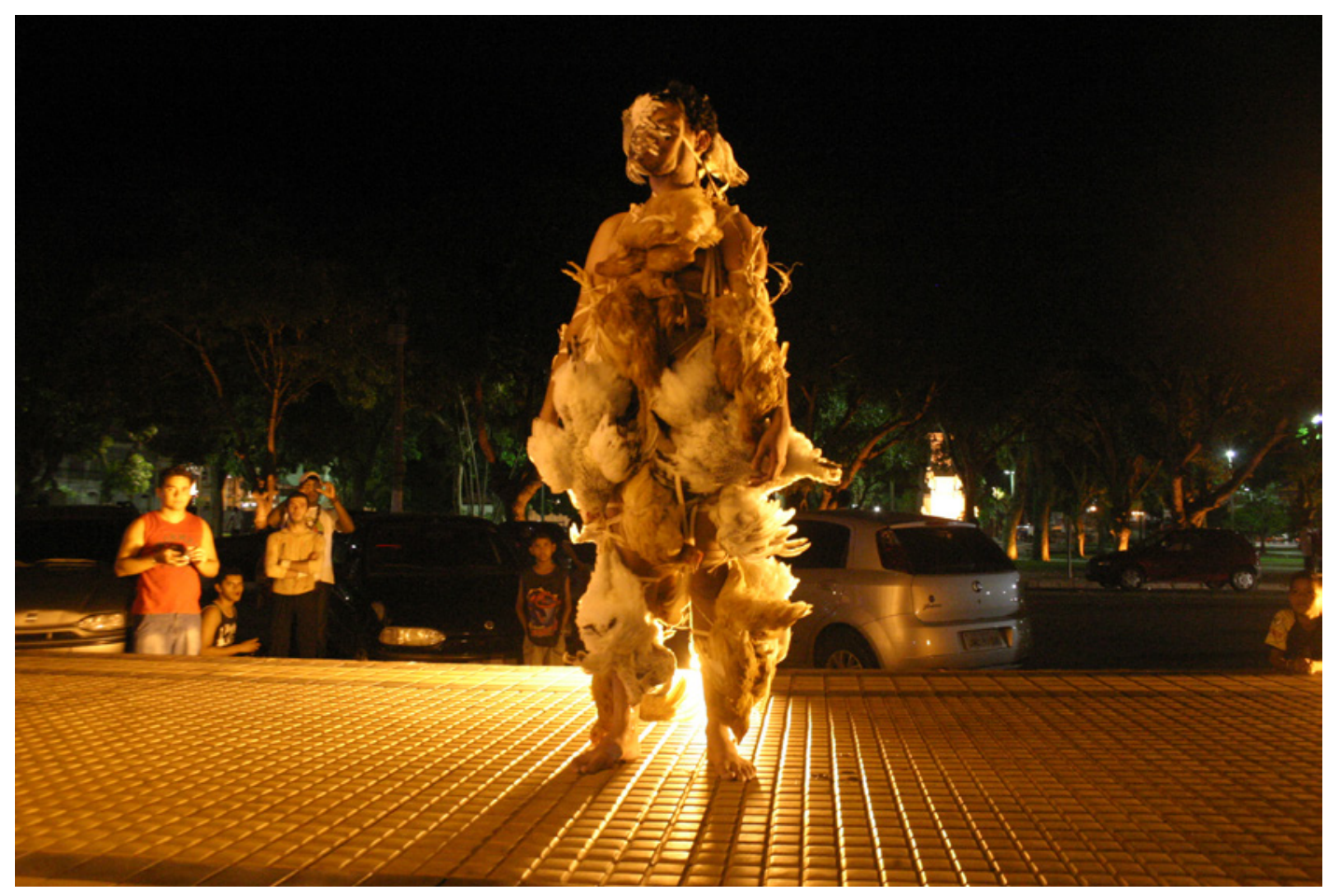

Figura 02 B. Gallus Sapiens Parte 02, de Victor De La Rocque, apresentado na 27o Edição do Salão Arte Pará. $2^{\circ}$ ato aparição, Come, Ainda Tens Tempo. Fotografia: Victor De La Rocque.

Válido acrescentar, além do mais, que, após uma série de tentativas de negociações com o poder público para a realização da performance neste espaço (todas estas tentativas ignoradas), o próprio performer teve de negociar com os moradores de rua, os quais transformaram o monumento em uma espécie de abrigo/ casa. Depois de autorizada a ação por estes residentes (e isto através da anuência de um líder local, o qual o recebeu, após brandir seu facão, para mostrar sua liderança), algo não menos inusitado ocorreu, pelo que pode ser lido pela fala de De La Rocque:

No dia da performance, muitos estavam por lá como de costume. Quando viram as galinhas vivas, ficaram loucos, pois as queriam para comer/vender, não sei objetivamente o que queriam. Após fazer a performance, todos vieram pra cima de mim, e daí apareceram vários canivetes, facas e o escambau. Foi algo que não tinha negociado, mas aconteceu. Depois que desci da mão, todos vieram pegar as galinhas, e foi uma loucura, por que cortavam os fios das galinhas que estavam amarradas e, às vezes, me cortavam e saíam correndo com a sua galinha. Foi uma loucura mesmo. Eu fiquei bastante assustado no momento, mas ao mesmo tempo percebi que aquilo tudo era consequência da minha ação naquele ambiente. Não sobrou nenhuma galinha nesse dia, todas foram levadas (Victor De La Rocque, Comunicação Pessoal).

O segundo ato-aparição, Come, Ainda Tens Tempo (Figura 02-B), ocorrido nos arredores do Museu Histórico do Pará (MHEP), levou este agora homem-chulo (termo utilizado pelo artista) buscar alimento, e cuja única oportunidade parecia ser mediante a entrada em um evento social e artístico (a Abertura do 26º Arte Pará). Em meio à fome e à ânsia por catar restos que pudessem aplacar seu vazio interior, outro tipo de vazio fez-se simbolizado, semelhante a tantos exemplos da arte contemporânea, exemplos os quais buscam a inserção no circuito oficial de mostras a qualquer custo (algo igualmente posto em ênfase pela primeira parte de seu projeto).

Mais uma vez, as críticas não declaradas e cínicas para a arte como salvação e confirmação artística, via institucionalização, pareceram-nos possíveis. E foram além, pois ilustraram espetáculos de pão e circo para uma ocasional capitalização imputada, cotidianamente, via miséria, 
sofrimento e tipos de samaritanismos falsos e autopromocionais do sistema das artes.

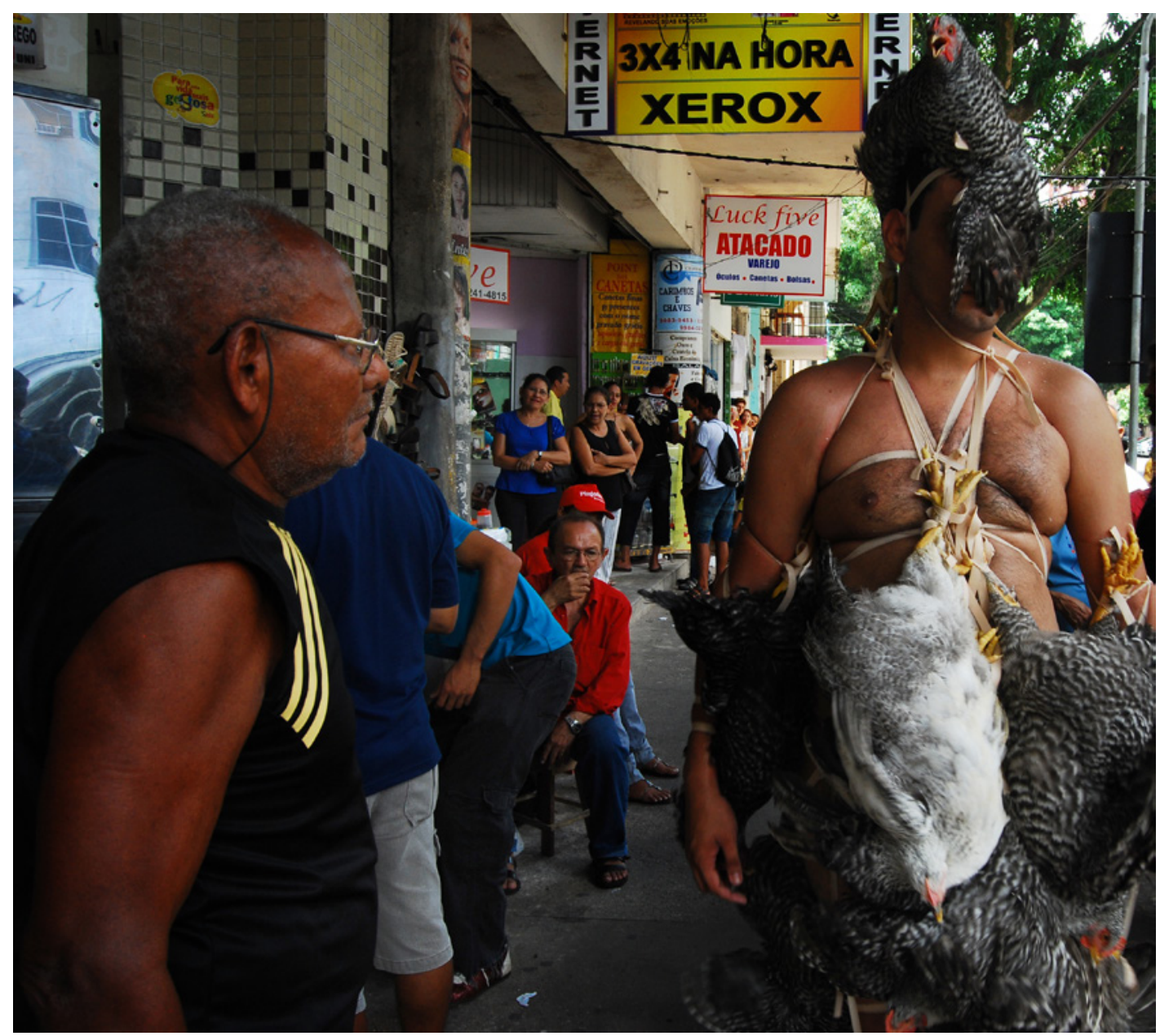

Figura 02 C. Gallus Sapiens Parte 02, de Victor De La Rocque, apresentado na 27º Edição do Salão Arte Pará. $3^{\circ}$ ato aparição, Entre os Meus e os Seus. Fotografia: Victor De La Rocque.

O terceiro ato-aparição, Entre os Meus e os Seus (Figura 02-C), deste roteiro com afinidades bergmanianas (e aqui a Trilogia do Silêncio ${ }^{12}$ parece, inevitavelmente, servir de paralelo a anunciar um trágico ciclo), já que nem Deus e nem a instituição das artes puderam mostrar interesse, buscou sua tentativa última de pedir ajuda em meio à coletividade. E, nesta tentativa, ironicamente, desnudou a condição de semelhança nos outros, portanto galiformes: sujeitos, habitantes comuns, os quais concedem ao personagem do artista nada além de surpresa e de desprezo, mesmo em meio a condições compartilhadas de luta para sobreviver em um mundo competitivo e, muitas vezes, opressor.

Com sua ação-passagem pela Avenida Presidente Vargas, local comercial e de grande circulação de pessoas e de transportes, mais seu consequente insucesso para ser acolhido, ainda que ostentando a sua nudez e desproteção, o ato de imolação se prenunciou no horizonte do artista-entidade como alternativa última. Sua existência em um ambiente saturado pelo desprezo e pelo repúdio, sonoramente seguido de aplausos como celebração da derrocada visível (o espetáculo pareceu ser aqui o único eixo a quebrar o torpor natural da vida em coletividade) não

12 Esta Trilogia é formada pelos filmes Através de um Espelho (1961), Luz de Inverno (1962) e O Silêncio (1963). Todas tratam sobre o silêncio de Deus ante o sofrimento e a dúvida humanas. 
deixavam dúvidas. Para além das críticas em torno da fetichização da tragédia, já que a mesma também é empregada como catalisadora para uma maior circulação de notícias vendáveis, a história-absurdo de De La Rocque pôde insinuar uma situação crônica, violenta e encarcerante acerca do modo de se viver contemporaneamente.

Sendo assim, seja em meio aos ruídos os quais pareciam confundir prazer e nojo, barulho este também evidenciado pelas críticas ${ }^{13}$ externas sofridas pelo artista quanto ao uso de aves em sua ação performática, pareceu não haver muito espaço para se pensar como este agenciamento artístico seria um discurso a reverberar hábitos, silêncios propugnados, códigos metafóricos e a (des)conexão vital de um conjunto orgânico que abarca artistas, curadores, críticos e visitantes, todos espectadores de si e de outros (Rancière 2012).

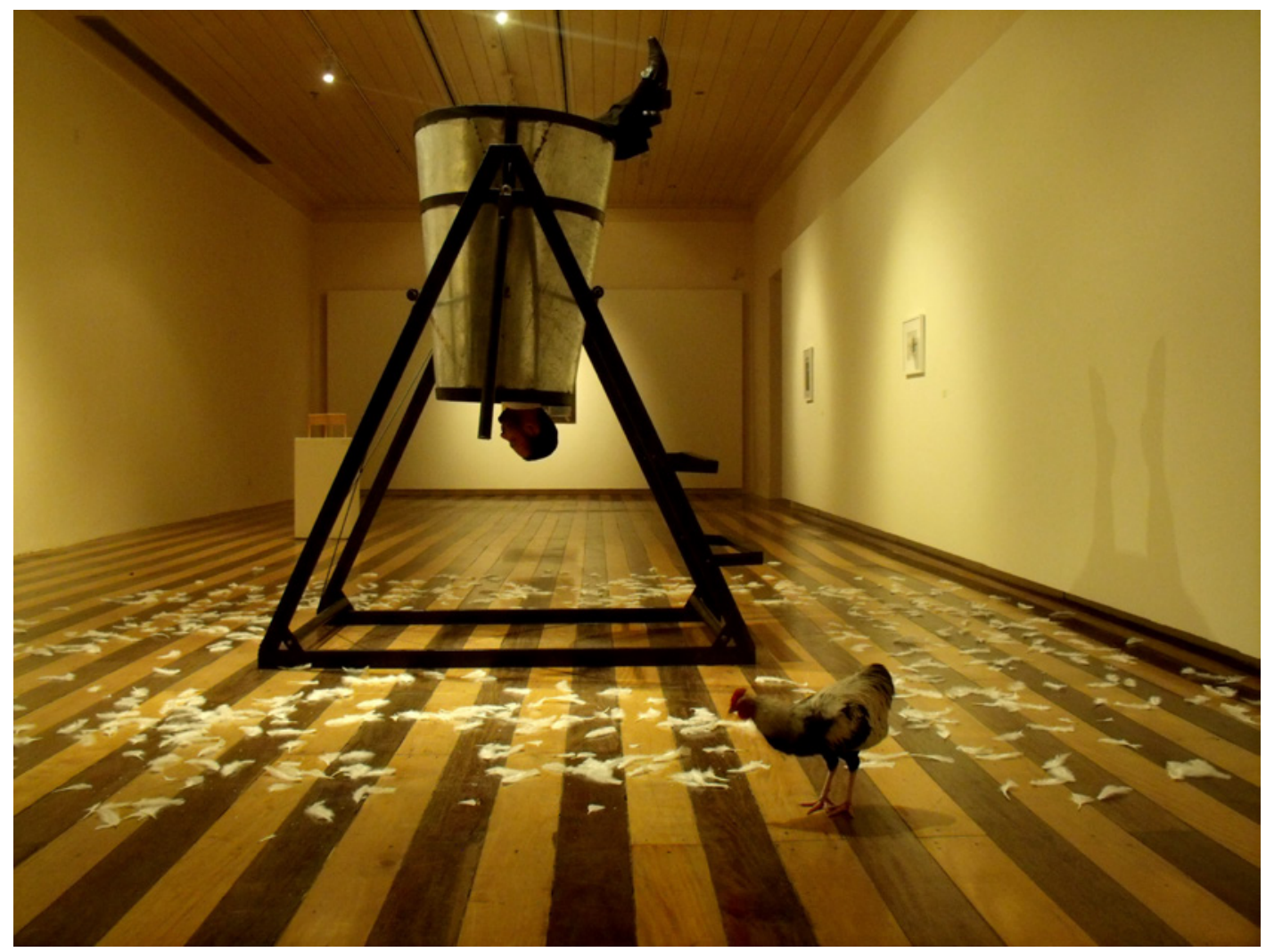

Figura 03. Momento Cone, performance integrante de Gallus Sapiens Parte 3, de Victor De La Rocque. Fotografia: John Fletcher.

\section{Gallus Sapiens Parte 03: o Abate}

Como término desta narrativa em torno do projeto de Victor De La Rocque, delineamos a terceira etapa de Gallus Sapiens, com sua performance integrante Momento Cone, apresentada,

13 As críticas sofridas pelo artista tiveram desde pedidos para a anulação de sua premiação no Salão Arte Pará, manifestações no hall de entrada do MASP-SP, até notas de repúdio por parte da Sociedade Brasileira dos Vegetarianos (SBV), do Jornal Gazeta de Vitória e da Agência de Notícias de Direitos Animais (ANDA), todos preocupados com a superfície das críticas e não com as dimensões de negligências sociais maiores praticadas em território nacional (o Monumento à Cabanagem, por exemplo, continua sem receber assistência para seus moradores). 
pela primeira vez, no 30 Salão Arte Pará, em 2011, sob curadoria de Ricardo Rezende, e depois, já em 2012, no Espaço Cultural da Casa das 11 Janelas (Figura 03), também em Belém, durante uma das apresentações do projeto Amazônia Lugar da Experiência, projeto este de autoria e curadoria de Orlando Maneschy.

Esta fase concluiu pelo sacrifício, enxergamos, uma história sobre os excessos, as banalidades e as agruras do homem urbano (e por que não dizer que pareceu se aproximar, em certos aspectos, do filme Persona ${ }^{14}$, também dirigido por Ingmar Bergman). Sua própria concretização matérica e conceitual não escapou de um marcador cultural local, quer seja de comprar galinhas recém abatidas em feiras locais para consumo, e demonstrou ser capaz de projetar dimensões autocríticas de estruturas de sentimentos ${ }^{15}$ de um mundo irregular e irregularmente conectado. Orlando Maneschy, um dos curadores envolvidos no processo de erupção da performance artística, observou, então, como "o artista ativou possibilidades e desejos, dúvidas e questionamentos, engendrando estranhamentos em nosso olhar sobre a vida” (2013: 42).

De maneira física, vale acrescentar, a obra incluiu uma réplica em escala humana de um matadouro de aves, objeto comumente encontrado, no seu tamanho original menor, em feiras livres de várias cidades do país; uma faca afiada presa à parede (Figura 04), similar às utilizadas nestes comércios para degolar as galinhas e os frangos, e "limpar" seus interiores; uma porção de penas para circundar o cone-matadouro, e, assim, criar um ambiente de sacrifício cumprido, ou mesmo de em progresso; um galo, bicho primeiro de onde saiu o homem, no sentido poético da ação, e que ainda agora possui um patamar hierárquico similar, já que lógica não seria uma palavra adequada para diferenciar o antes e o depois desta ave com o seu duplo/ dúbio, o gallus sapiens; e o próprio artista como personagem/ presença (um gallus vivo, mas em seus derradeiros instantes), com o intuito de servir seja de mercadoria em oferta, de vítima, de vitrine e de espetáculo, de espelho, de escárnio, de piada, de horizonte de eventos, de monumento para ser evocado/ se pedir perdão de um genuflexório.

Durante o decorrer da feitura do cone em escala humana, De La Rocque (Comunicação Pessoal) ainda revelou que a ideia de roldanas ${ }^{16}$ para este cone, as quais melhor fariam com que o local de depósito do corpo do artista pudesse ser inclinado para sua entrada, foi indispensável. Foi esta solução, mais especificamente, que facilitou a praticidade da obra para uma permanência física mais suportável (permanência esta que durou 50 minutos na primeira exibição, durante o Arte Pará, e 20 minutos, na segunda exibição, durante o projeto Amazônia Lugar da Experiência).

Outro aspecto igualmente necessário para acrescentar é o de que esta terceira etapa do projeto do artista previu sua execução em duas feiras belemenses e em um terceiro local da cidade denominado Ponte do Galo, conhecido por seu alto grau de criminalidade. Entretanto, muito mais em virtude de uma limitação financeira para custear toda uma equipe necessária para a produção e execução da ação nestes locais, o artista teve de manter em suspenso tais planos (po-

14 Persona, de 1966, fala sobre a personagem vivida pela atriz Liv Ullmann. De teor existencialista, esta obra mostra o silêncio da personagem como forma de ato único e morte para evitar a sua ficcionalização e, portanto, o não entendimento pelo olhar do outro.

15 Este termo, cunhado por Raymond Williams (1989) busca evidenciar modos de ver o mundo em meio às estruturas dinâmicas das relações sociais.

16 Segundo relato de De La Rocque, esta ideia veio de um artista e amigo seu, Josynaldo Ferreira. Para a criação do cone, o artista contou com a ajuda de Roberto Miralha, tio de Luciana Magno, amiga próxima ao artista. 
rém com o intuito de efetivá-los mais à frente, condicionado pela possibilidade real de recurso) e ilustrou um indicativo muito próprio do fazer arte no Brasil: exercício, em um sentido expandido, fragilizado pela ainda pequena quantidade de investimentos particulares em nomes de fora dos holofotes da arte; dependência muito mais clara em políticas de editais artísticos, salões e prêmios; e a consequente execução de processos plásticos mais em situações que lhes são possíveis, porém raramente ideais, tendo o artista como maior e, às vezes, único investidor (situação, claro, que não se aplica inteiramente a nomes os quais foram assimilados pela indústria de massa e beneficiados pela incoerente especulação do mercado e do hype) (ver Cocchiarale 2000).

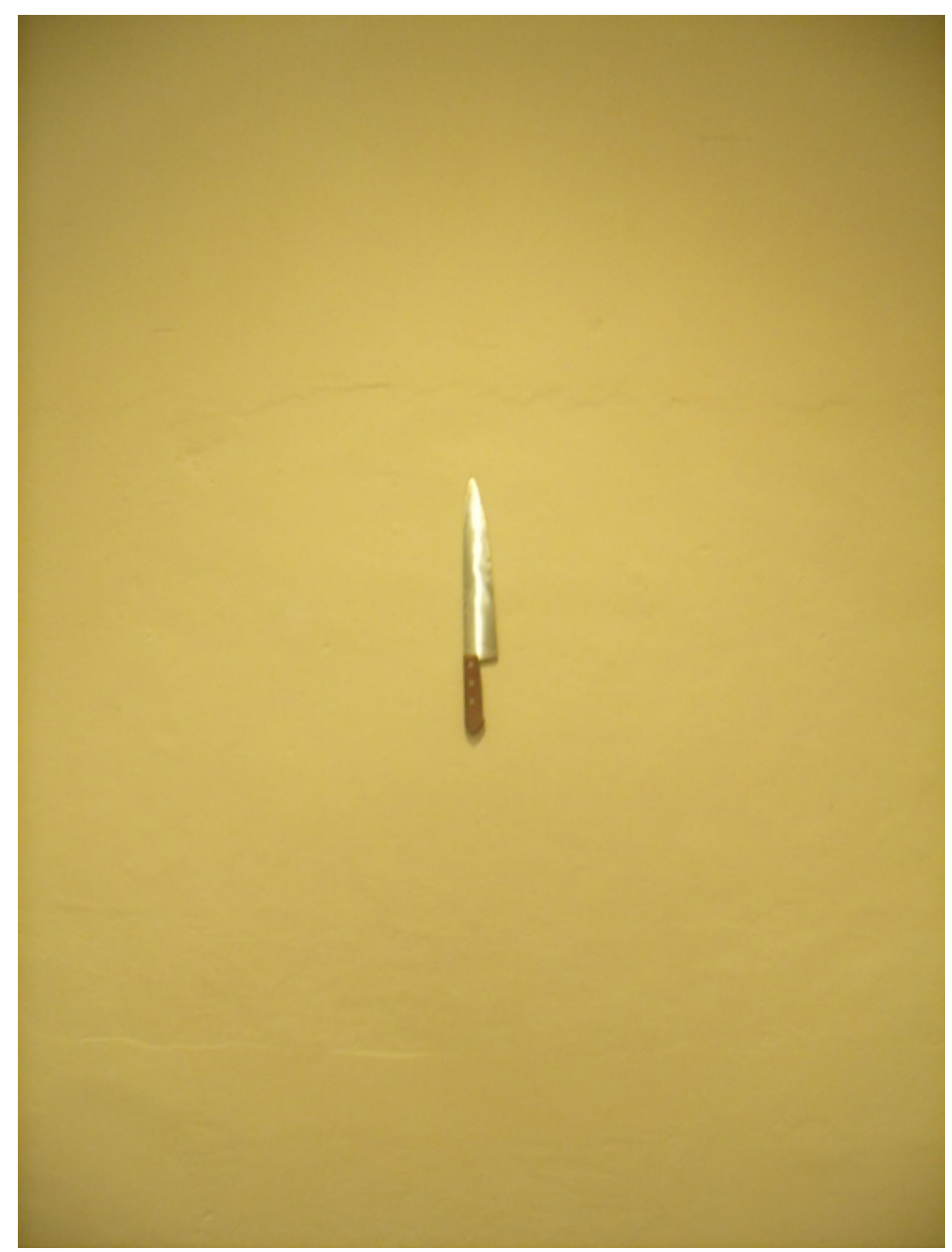

Figura 04. Detalhe da faca presa à parede, parte componente de Gallus Sapiens Parte 3, de Victor De La Rocque. Fotografia: John Fletcher.

De qualquer forma, de um ponto de vista não menos cheio de significados, as críticas empreendidas pelo enredo do artista, em um aspecto mesmo conceitual, foram, então, reveladas em outro prático, durante a sua execução e negociação com as diversas etapas (tanto psicológicas do idealizador, quanto sociais) para trafegar pelo circuito das artes: materializaram os vai e vêm, deliberadamente incongruentes, entre um estado de se ver às cegas, tateando, para sobreviver em um mundo marcado por micro colonialidades de poder, já que a única opção é a de dançar conforme a música; e um óbito salutar por, inúmeras vezes, servir de exemplo semelhante quando nos vemos lançados em banquetes de predadores para servir ora de espetáculo, ora de mártires de reputações duvidosas. 
Mesmo quando da não ocorrência da performance em seus três espaços públicos, a poética de Victor De La Rocque pôde, complementarmente, ser capaz de gerar dramaticidade silenciosa e fúnebre e manter vestígios de um banquete/ sacrifício, como se trouxesse à tona o episódio de Orfeu após a passagem das Bacantes. Seu encerramento narrativo, ainda que na dimensão unicamente matérica, sem o sujeito-homem e o sujeito-bicho, ilustraram um conglomerado de potências sígnicas, muito tributárias de uma interpretação terceira (ver Bhabha, 2003), contextual, individualizada, de acordo com quem observa e traz, ao seu remonte narrativo, suas memórias, repertórios e imaginários diversos (Rancière 2012).

E foi, de certa forma, em seu entre campo da iminência, trecho aproximável do quase ser, quase vir à tona, quase sair de uma condição de chiaroscuro, que o pressuposto de Gallus Sapiens se mostrou para nós politizante, cínico, ambiguamente real, imaginário e tátil. Como havia informado o artista no decorrer de suas ações performáticas, o momento cone, realmente, era inevitável.

\title{
Algumas Considerações
}

\begin{abstract}
Las calles resultan meras extensiones de nuestro laboratorio de performance; galerías sin muros. Muchos de nosotros nos consideramos activistas, pero nuestras estrategias de comunicación $y$ lenguajes experimentales son considerablemente distintos de aquellos utilizados por los activistas politicos. En resumen, nosotros somos lo que otros no son, decimos lo que otros no dicen, y ocupamos espacios culturales que, por lo general, son ignorados o depreciados. Debido a esto, nuestras múltiples comunidades están constituidas por refugiados estéticos, politicos, étnicos y de género (Gómez-Peña 2005: 203).
\end{abstract}

O Projeto Gallus Sapiens, de Victor De La Rocque, como pôde ser pontuado neste artigo, é minado de entendimentos, possui alta carga política e artística, e se coloca como um vagalume a emanar pequenas luzes em meio a um mundo saturado de holofotes que cegam (ou trevas, dependendo do olhar), entorpecem e geram deuses falsos.

Efetivo ao ato de simplesmente viver o pensamentocomocorpointeiro, fazendo uso de uma expressão de Beatriz de Medeiros (2011), pelo menos dentro deste presente recorte, o projeto não cede às tentativas de higienizações de muitos processos artísticos da atualidade, nem evita o conflito, o corpo a corpo, pois a integridade física do artista também é posta à prova (algo que pode ser muito bem exemplificado pelo episódio inusitado de sua ação artística no Monumento à Cabanagem, conforme abordado anteriormente) no próprio tecido vivo da urbe. E observado o fato de não haver uma máquina por trás de todo o processo artístico, diminuindo sua potência enquanto vida caótica e sem controles, tanto melhor para trazer como dados os conflitos reais surgidos pelos caminhos e descaminhos de se viver em um mundo desigual, posto às margens dos centros geopolíticos, inclusive nacionais.

Alguns autores, como Foster (2014), podem ter oportunamente pontuado que as intenções do engajamento político e da transgressão institucional das artes podem sofrer um enfraquecimento por sua recodificação para uma narrativa de clientelismo ideológico ou por sua absorção 
por um mercado artístico crescente. Todavia, não podemos esquecer de colocar este enunciado em perspectiva, pois seu teor também generalista, conforme destacado por Marcus (2004), igualmente revela tanto um ressentimento antropológico tradicional, quanto uma caricatura reducionista em relação às subjetividades e atividades multilocalizadas que compõem os diversos atores no espaço da criação artística.

Marcus (2004), por conseguinte, bem evidenciou como as relações entre antropologia e arte, e, mais especificamente, entre antropologia e performance tornaram e tornam instáveis os ideais reguladores tradicionais do fazer antropológico. Estas instabilidades, muitas em virtude da falência do caráter folclórico dominante na antropologia, já que um espaço para se produzir pensamentos socialmente engajados se tornou um operador de subversão da cultura e da antropologia mesma, podem ser muito bem exemplificadas em Gallus Sapiens e em seu duplo princípio: o da suspensão da crença, onde o fruidor pode se envolver com a ação performativa; e o do prazer da confusão, onde o fruidor, já familiar com a performance, está preparado para apreciar o que não entende, com a potência de deslocar sua experiência para a transformação política (ver também Kirshenblatt-Gimblett 1998; Gómez-Peña 2005).

Podemos, nesse sentido, ainda relacionar as três etapas do trabalho de De La Rocque com algumas das características do drama social, analisadas por Turner (1987). Tais características, evidenciadas pelos momentos mais críticos de uma sociedade, revelam uma estreita relação entre ritual e conflito nos seguintes moldes: ruptura, intensificação da crise, ação remediadora e reintegração possivelmente trágica. Analogamente, esta narrativa científica não deixa de possibilitar muitas aproximações com a do artista, quer seja a de seu personagem galiforme, o qual caminha desde a ruptura ao sacrifício, passando pelos mais diversos tipos de sujeição e de tentativa de reconciliação em falência - a crise como que a produzir um distanciamento reflexivo sobre a estrutura social.

Outro aspecto não menos relevante para esta leitura, para além das engrenagens artísticas, evidencia como performance e performer são as duas caras de uma mesma moeda política e estética, a qual atinge públicos integrais e públicos acidentais (Schechner 2006). Esta acepção da arte como veículo discursivo declaradamente político, pode ser lida como operação capaz de comentar ou ilustrar um posicionamento crítico, por vezes, resistente quanto aos preceitos sociais transvalorados; e, por vezes, como jocosidade cínica ante um modelo social em crise e sem prazo de validade para seu término.

Assim como um texto ou uma imagem nunca termina de dizer algo, dentro de encontros que são acontecimentos em eternos estados diferenciais, as ações empreendidas por Victor De La Rocque se caracterizaram por ser terreno fértil para germinar linguagens, códigos e vertigens. Embora precisemos constantemente nos alertar quanto ao desempenho de nossas retóricas sobre as ideias dos outros - elas dão ênfase não ao processo de criação de obras, mas sim às técnicas pelas quais uma obra se torna comunicável, e aqui encontramos os mais variados artifícios para se buscar reconhecimento no mundo ficcional da escrita da imagem -, o Projeto Gallus Sapiens é realidade séria e debochada, conflituosa, permeada, precariamente, por imaginações autorais, compartilhadas. Sua concretização no território da arte contemporânea paraense é, destacamos, um mosaico de experiências possíveis e alternativas para se visibilizar um estar-junto beligerante. 


\section{ReferênCias Biblográficas}

Agamben, G. 2009. O que é o Contemporâneo? e Outros Ensaios. Chapecó, Santa Catarina: Argos. Auslander, P. 2006. The Performativity of Performance Documentation. Performing Arts Journal, n. 84: 01-10.

Bhabha, H. K. 2003. Como o Novo Entra no Mundo: O Espaço Pós-Moderno, os Tempos Pós-Coloniais e as Provações da Tradução Cultural. In: Bhabha, H. K. O Local da Cultura. Belo Horizonte: UFMG: 292-325.

2012. Arte e Iminência. In: Catálogo da 30 Bienal de São Paulo: A Iminência das Poéticas. São Paulo: Fundação Bienal de São Paulo: 20-25.

Carlson, M. 2010. Performance: Uma Introdução Crítica. Belo Horizonte: UFMG.

Chaves, E. 2013. Michael Foucault e a Verdade Cínica. Campinas: PHI.

Cocchiarale, F. 2000. Da Adversidade Vivemos. In: Hollanda, H. B.; Resende, B. (Org.). Artelatina: Cultura, Globalização e Identidades. Rio de Janeiro: Aeroplano: 96-112.

Foster, H. 2014. O Artista como Etnógrafo. In: FOSTER, H. O Retorno do Real. São Paulo: Cosac Naify: 159-186.

Foucault, M. 2014. Aulas sobre a Vontade de Saber. São Paulo: WMF Martins Fontes.

García Canclini, N. 2012. A Sociedade sem Relato: Antropologia e Estética da Iminência. São Paulo: Edusp.

Geertz, C. 2008. A Arte Como um Sistema Cultural. In: Geertz, C. O Saber Local: Novos Ensaios em Antropologia Interpretativa. Petrópolis: Vozes.

Goldberg, R. 2006. A Arte da Performance: Do Futurismo ao Presente. São Paulo: Martins Fontes. Gómez-Peña, G. 2005. En Defesa del Arte del Performance. Horizontes Antropológicos, v. 11, n. 24, Porto Alegre: 199-226.

Hall, S. A. 2009. Modernidade e os seus Outros: Três "Momentos" na História das Artes na Diáspora Negra do Pós-Guerra. Artafrica, Centro de Estudos Comparatistas, Faculdade de Letras, Universidade de Lisboa: 01-26.

Kirshenblatt-Gimblett, B. 1998. The Ethnographic Burlesque. The Drama Review: A Journal of Performance Studies, v. 02, n. 42: 175-180.

Lotufo, J. J. 2013. Habitando Interstícios: A Arte da Performance entre Fronteiras. In: VI Seminário Nacional de Pesquisa em Arte e Cultura Visual, Goiânia. Anais do VI Seminário de Pesquisa em Arte e Cultura Visual. Goiânia: UFG, FAV: 1159-1170.

Lucero, M.E. 2011. Decoloniality in Latin American Art. Southern Perspectives. Disponível em < http://www.southernperspectives.net/tag/modernism>.

Maiorana, R.; Oliveira, D.; Maneschy, O.; Sequeira, A.; Franco, E. (Org.). 2009. 27 Arte Pará. Belém: Fundação Rômulo Maiorana.

Maneschy, O. 2009. Trânsitos e Irradiações na Arte. In: Maiorana, R.; Oliveira, D.; Maneschy, O.; Sequeira, A.; Franco, E. (Org.). Arte Pará 2008. Belém: Fundação Rômulo Maiorana: 23-48.

2013. Notas Sobre o Gallus Sapiens. In: Maneschy, O. (Org.). Outra Natureza: 6 Diálogos Sobre a Amazônia. Belém: Banco da Amazônia.

Marcus, G. E. 2004. O intercâmbio entre Arte e Antropologia: Como a Pesquisa de Campo em Artes Cênicas pode Informar a Reinvenção da Pesquisa de Campo em Antropologia. Revista de Antropologia, São Paulo, v. 47, n. 01: 133-158.

Medeiros, M. B. 2011. Pesquisa em Arte, Linguagem da Arte ou Como Escrever sobre o Pensamentocomocorpointeiro. In: Aquino, F.; Medeiros, M. B. (Org.). Corpos Informáticos: Performance, Corpo, Política. Brasilia: PPG-ARTE/ UnB: 15-36. 
Mignolo, W. 2010. Desobediencia Epistémica: Retórica de La Modernidad, Lógica de La Colonialidad y Gramática de La Descolonialidad. Buenos Aires: Del Signo.

Mouffe, C. 2007. Art Activism and Agonistic Spaces. Art E Research, v. 1, n. 02.

Pelbart, P. P. 2014. Do Livro como Experiência à Vida como Experimentação. Revista Cult, São Paulo, n. 191: 34-36.

Phelan, P. 1993. Unmarked: The Politics of Performance. London; New York: Routledge.

Plaza, J. 1987. Tradução Intersemiótica. São Paulo: Perspectiva.

Ramirez, M. C. 2004. Tactics for Thriving on Adversity: Conceptualism in Latin America, 1960-1980. In: Ramírez, M. C.; Olea, H. Inverted Utopias: Avant-Garde Art in Latin America. Houston: Yale University Press, The Museum of Fine Arts: 425-439.

Rancière, J. 2012. O Espectador Emancipado. São Paulo: WMF Martins Fontes.

Said, E. 1994. Culture and Imperialism. New York: Vintage.

Sarlo, B. 2000. Cenas da Vida Pós-Moderna: Intelectuais, Arte e Vídeo-Cultura na Argentina. São Paulo: Editora UFRJ.

Sarraf, A. 2012. Cosmologias Afroindígenas na Amazônia Marajoara. Projeto História, 44: 197226.

Schechner, R. 2006. Performance Studies: An Introduction. New York, London: Routledge.

Schneider, A. 2008. Three Modes of Experimentation with Art and Ethnography. Journal of the Royal Anthopological Institute, 14: 171-194.

Schneider, A.; Wright, C. 2010. Between Art and Anthropology: Contemporary Etnographic Practice. New York: Berg.

Sibila, P. 2010 O Artista como Performer: Dilemas do Eu Espetacular na Arte Contemporânea. In: Labra, D. (Org.). Performance Presente Futuro. Rio de Janeiro: Aeroplano; Oi Futuro: 167-217.

Silva, R. A. 2005. Entre "Artes" e "Ciências": A Noção de Performance no Campo das Ciências Sociais. Horizontes Antropológicos, v. 11, n. 24, Porto Alegre: 35-65.

Rocha, A. L. C.; Eckert, C. 1998. A Interioridade da Experiência Profissional do Antropólogo como Condição da Produção Etnográfica. Antropologia 2 (41): 107-136.

Tiburi,M. 2014. Michel Foucault e a verdade cínica de Ernani Chaves. Revista Cult, São Paulo. Disponível em <http://revistacult.uol.com.br/home/2014/03/michel-foucault-e-a-verdade-cinica-de-ernani-chaves/>. Acesso em 05/06/2014.

Turner, V. The Anthropology of Performance. New York: PAJ Publications, 1987.

Williams, R. 1989. The Politics of Modernism: Against the New Conformists. London: Verso.

\section{Gallus SAPIENS: NA ARTISTICPROJect OF Victor de LA ROCQUE, SEEN FROM AN ANTHROPOLOGICAL PERSPECTIVE}

\footnotetext{
This article aims to outline an interpretative look onto the artistic project Gallus Sapiens, conceived by the artist Victor De La Rocque. This project, in each of its three distinct parts, generates political, critical and poetic meanings, besides signalling culturalities of non-hegemonic countries; structural and political factors over conditions of perception; incident pedagogies; and politicized and politicizing dialogues for different social groups. Using Clifford Geertz's interpretative methodology, questioned by postcolonial and decolonial perspectives of authors such as Walter Mignolo, Homi Bhabha and Nestor Garcia Canclini, the article draws on scholars from the field of philosophy, such as Michel Foucault, Ernani Chaves and Jacques Rancière; others from the anthropology, such as Arnd Schneider Christopher Wright, George Marcus and Victor Turner; and from the visual arts, such as Roselee
} 
Goldberg, Beatriz de Medeiros and Orlando Maneschy. The Gallus Sapiens project, permeated by chaotic and conflicting meanings, is analyzed from the perspective of being-together in its essence, tied to the paths and non-paths of living in an irregular world, put on the borders of geopolitical and national centres.

Keywords: Gallus Sapiens, Victor De La Rocque, contemporary art, Interpretation

Recebido em: 2015-01-31

Aceitado em: 2015-05-29 